\title{
Crenças sobre o ensino-aprendizagem de espanhol em uma escola pública
}

\author{
Beliefs about Teaching and Learning \\ Spanish in a Public School
}

Fernando Zolin-Vesz*

Instituto Federal de Educação, Ciência e Tecnologia de Mato Grosso

Cuiabá - Mato Grosso / Brasil

RESUMO: O objetivo deste artigo é buscar compreender, partindo dos relatos da professora de espanhol, da coordenadora pedagógica e da diretora de uma escola pública que, desde 2000, oferece o idioma como disciplina obrigatória e única língua estrangeira de sua matriz curricular do $6^{\circ}$ ao $9^{\circ}$ ano, duas crenças que envolvem a adoção do ensino da língua nessa escola. Crenças são entendidas como produtos sociais, históricos e políticos conectados aos contextos sociopolíticos mais abrangentes (BARCELOS; KALAJA, 2011). Os resultados sugerem que o ensino do espanhol nessa escola parece constituir discursivamente um artifício para a manutenção da estratificação social e do status quo, dado que os relatos dos participantes da pesquisa não abrem o ensejo de transformação social.

PALAVRAS-CHAVE: crenças sobre ensino e aprendizagem de línguas; espanhol.

ABSTRACT: The purpose of this paper is to understand, through the Spanish teacher's, the pedagogic coordinator's, and the principal's accounts, two beliefs about the teaching and learning of Spanish in an elementary public school that has included Spanish as a foreign language in its syllabus since 2000. Beliefs are seen as socially historical and political products, connected to the broad sociopolitical contexts (BARCELOS; KALAJA, 2011). Results suggest that the teaching of Spanish as a foreign language in that school seems to be discursively an artifice to maintain the social stratification and the status quo.

KEYWORDS: beliefs about language teaching and learning; Spanish as a foreign language.

* fernando.vesz@blv.ifmt.edu.br 


\section{Introdução}

A assinatura do Tratado de Assunção, em 1991, que resultou no Acordo do Mercado Comum do Sul (Mercosul) entre Brasil, Argentina, Uruguai e Paraguai, é apontada como o acontecimento que modifica significativamente o percurso histórico da presença do espanhol como disciplina nas escolas brasileiras (PARAQUETT, 2009), uma vez que é considerado o propulsor do ensino e da aprendizagem da língua no país (VILLA; DEL VALLE, 2008). O acordo pretendia não apenas promover o livre comércio e o fluxo aberto de pessoas e bens entre os países membros, mas também alcançar uma integração linguística e educacional, principalmente a difusão do aprendizado dos idiomas oficiais (espanhol e português) através dos sistemas educacionais de cada país.

Desde então, esforços têm sido realizados para o fortalecimento dessa integração regional, principalmente no sentido de dotar um papel político ao ensino do espanhol na educação brasileira - o de elemento de integração regional. Dentre esses esforços, destacam-se a homologação da Lei n. 11.161, de 2005, que determina a oferta obrigatória do espanhol pelas escolas nos currículos plenos do ensino médio e também faculta a oferta do idioma ao ensino fundamental do $6^{\circ}$ ao $9^{\circ}$ ano, e a publicação das Orientações Curriculares Nacionais para o Ensino Médio - OCEM (2006), que prescrevem o ensino de espanhol nos níveis fundamental e médio do sistema educacional brasileiro como um espaço para a educação linguística de modo a contribuir para a denúncia da imposição de uma única norma e, sobretudo, para a superação de crenças que circulam na sociedade, como a suposta facilidade para aprender espanhol.

Neste artigo, ${ }^{1}$ proponho, partindo da análise dos relatos da professora de espanhol, da coordenadora pedagógica e da diretora de uma escola pública que, desde 2000, oferece espanhol como disciplina obrigatória e única língua estrangeira de sua matriz curricular do $6^{\circ}$ ao $9^{\circ}$ ano, buscar compreender duas crenças que envolvem a adoção do ensino da língua nessa escola - (1) a aprendizagem do espanhol possibilita inserir-se no mercado (informal) de trabalho, e (2) o espanhol é a língua estrangeira que melhor atende aos alunos

\footnotetext{
${ }^{1}$ Este artigo é um recorte modificado de minha dissertação intitulada Crenças sobre o espanhol na escola pública: "Bem-vindos ao mundo dos sonhos e das [im]possibilidades", defendida no Programa de Pós-Graduação em Estudos de Linguagem da Universidade Federal de Mato Grosso (UFMT), sob orientação da Profa. Dra. Ana Antônia de Assis Peterson.
} 
de escola pública. Inicialmente, apresento a definição e a natureza das crenças sobre ensino e aprendizagem de línguas que orientam a análise, e a compreensão do papel político sobre o ensino e aprendizagem do espanhol no Brasil como elemento de integração regional. $\mathrm{Na}$ sequência, apresento o contexto e a metodologia da pesquisa. Por fim, discuto cada uma das crenças identificadas e o papel atribuído à introdução do espanhol na escola em que ocorreu a investigação.

\section{A investigação de crenças sobre ensino e aprendizagem de línguas}

A principal implicação da pesquisa de crenças sobre ensino e aprendizagem de línguas é, segundo Barcelos (2004), a possibilidade de criar espaços para alunos, futuros professores e até mesmo professores em exercício questionarem suas crenças, crenças sobre ensino etc., "[...] na tentativa de entender as crenças que nos cercam em nosso meio social, as consequências dessas crenças para nosso desenvolvimento como pessoas, como cidadãos, como professores e alunos" (BARCELOS, 2004, p. 146).

Apesar de não haver uma definição única de crenças, Barcelos aponta duas observaçōes gerais: a primeira é de que "as definiçōes [...] se referem à natureza da linguagem e ao ensino/aprendizagem de línguas", e a segunda é de que "as crenças não são somente um conceito cognitivo, mas também social, porque nascem [...] de nossa interação com o contexto e da nossa capacidade de refletir e pensar sobre o que nos cerca" (BARCELOS, 2004, p. 132). Assim sendo, a definição de crenças que orienta essa análise é a que a autora tem adotado nos últimos anos:

[Crenças são] uma forma de pensamento, construções da realidade, maneiras de ver e perceber o mundo e seus fenômenos, co-construídas em nossas experiências resultantes de um processo interativo de interpretação e (re)significação. Como tal, crenças são sociais (mas também individuais), dinâmicas, contextuais e paradoxais (BARCELOS, 2006, p. 18; 2007, p. 113).

Em consonância com Barcelos, acredito que essa definição permite delinear um perfil diferente da natureza das crenças. Enquanto os primeiros estudos e definições concebiam crenças como estruturas mentais, estáveis, imutáveis e distintas do conhecimento, o conceito proposto por Barcelos indica uma perspectiva mais situada e contextual. Crenças, portanto, 
retomando o conceito da autora, são experienciais, pois constituem parte das construções e reconstruções de nossas experiências, e são socialmente construídas e situadas contextualmente, ou seja, incorporam as perspectivas sociais, pois nascem no contexto da interação e na relação com os grupos sociais. Barcelos e Kalaja (2011) acrescentam a essa concepção que crenças são relacionadas com os contextos micro e macropolíticos, pois são produtos sociais, históricos e políticos conectados aos contextos sociopolíticos mais abrangentes.

A pesquisa de Pan e Block (2011) corrobora essa concepção de crenças trazida por Barcelos e Kalaja. Ao investigar as crenças de professores e alunos de inglês na China, os autores concluem que crenças necessariamente se relacionam com o contexto sociopolítico mais abrangente e sugerem uma dimensão sociodiscursiva na compreensão e análise de crenças sobre ensino e aprendizagem de línguas. As crenças que identificaram, como "o inglês é uma nova habilidade necessária até mesmo em pequenos vilarejos" e a insatisfação com as práticas de ensino correntes, são inevitavelmente influenciadas, segundo os autores, pelo contexto sociopolítico em que a China se encontra, ou seja, seu recente desenvolvimento econômico, sua necessidade de internacionalização e a acelerada mudança social provocada no decorrer da organização dos Jogos Olímpicos de 2008. Crenças, portanto, são produtos sociais e políticos. É nessa concepção do conceito de crenças sobre ensino e aprendizagem de línguas, portanto, que esta pesquisa está inserida.

\section{O ensino de espanhol como elemento de integração regional}

Segundo autores como Villa e del Valle (2008), apesar de o nascimento do Mercosul ter sido o propulsor do ensino e da aprendizagem do espanhol no Brasil, a visibilidade - seja pelo número de acordos seja pela cobertura da mídia - da promoção da língua no Brasil é conferida a instituições espanholas. As ações dessas instituições resultam no monopólio tanto da elaboração de material didático, e do consequente privilégio da variedade europeia da língua, quanto da formação de um imaginário sobre o espanhol no Brasil. Esse imaginário, na esteira de Del Valle (2007), está ancorado nas principais estratégias da Real Academia Española (RAE) e do Instituto Cervantes, órgão oficial do Ministério de Educação da Espanha, para fomentar o espanhol como língua estrangeira fora do território nacional e dotar o idioma de uma imagem que engloba três características principais: a concórdia, o universalismo e a rentabilidade. 
A primeira característica assume a imagem do espanhol como uma "língua de encontro", ou seja, instrumento de comunicação que possibilita o diálogo e a convivência harmônica próprios de uma pátria comum. Assim, o espanhol é considerado a língua comum do mundo hispânico, em que a Espanha desempenha papel central, servindo como modo de expressão a múltiplas culturas. Simboliza o espírito de concórdia e de democracia.

A segunda característica afirma o caráter global do espanhol como uma língua em expansão. Esta projeção global, na lente do autor, resulta tanto de sua presença nos países que constituem o mundo hispânico quanto de sua capacidade de expansão, exemplificada com sua presença, em países como Brasil e Estados Unidos, e seu constante crescimento como língua estrangeira, no sistema educativo de vários países.

Por fim, a terceira característica encadeia o espanhol à sua condição de recurso econômico, ou seja, uma língua útil e rentável que pode constituir valioso capital cultural para quem a detém.

Esse investimento espanhol na promoção da língua no país teria culminado, de acordo com Villa e Del Valle (2008), na sanção da Lei n. 11.161, de 5 de agosto de 2005. Desde então, conforme os autores, o Brasil se tornou uma prioridade para as agências espanholas. Contudo, de acordo com Lagares (2010), esse investimento espanhol na promoção da língua no país tem provocado reaçóes que envolvem, principalmente, o modo de abordar a língua nos processos de ensino e aprendizagem e o seu papel político na educação brasileira.

Na primeira categoria, o autor enfatiza a operação de redução da língua espanhola, verificada principalmente em materiais didáticos, em que a variação aparece apenas como um fenômeno marginal e não como constitutivo da realidade linguística. Nesse sentido, Lagares (2010) identifica duas posiçóes contrárias nas abordagens de ensino do espanhol para brasileiros: uma em que a ênfase ocorre no ensino de um espanhol homogêneo para a comunicação internacional, defendida pelos órgãos de difusão internacional da língua do governo espanhol, e outra, expressa em documentos que regulam o ensino no Brasil, em que a ênfase ocorre em uma educação linguística que desconstrói essa imagem unitária.

A segunda categoria apresentada por Lagares (2010) envolve a aspiração do ensino de espanhol no Brasil como elemento de integração regional. Nesse sentido, Gil (2009), ao analisar o ensino de inglês, de português e de espanhol como línguas estrangeiras no Brasil e na Argentina, propõe que o espanhol e o português, a fim de criar uma consciência da importância das mesmas, não sejam 
vistos como línguas estrangeiras, mas como línguas regionais ou línguas de integração. Ao mesmo tempo, a autora observa que uma questão fundamental para esse propósito seria que as mudanças não se limitassem a uma mera substituição de línguas, ou seja, do inglês pelo espanhol no Brasil e do inglês pelo português na Argentina. ${ }^{2}$ Segundo a autora, isso implicaria na continuidade de práticas pedagógicas anacrônicas e pouco efetivas. Gil sugere, portanto, que essas línguas possibilitem um ensino-aprendizagem efetivo e adequado por meio das suas funçōes sociais - como elementos de integração regional.

Entretanto, a análise dos relatos da professora de espanhol, da coordenadora pedagógica e da diretora sugere outro papel para a introdução do ensino de espanhol na escola em que atuam. Esse novo papel encarta duas crenças principais - (1) a aprendizagem do espanhol possibilita inserir-se no mercado (informal) de trabalho, e (2) o espanhol é a língua estrangeira que melhor atende aos alunos de escola pública.

\section{O contexto e a metodologia da pesquisa}

Assim como a maioria dos estudos sobre crenças no Brasil, esta pesquisa é de base interpretativo-qualitativa. O foco, portanto, está centrado na compreensão de como as pessoas percebem o mundo e significam sua vida a partir de suas crenças. Dessa forma, crenças são entendidas como condicionadas situacionalmente, já que representam momentos específicos da vida dos participantes da pesquisa relacionados com suas interpretaçôes sobre sua experiência de aprender línguas em contextos educacionais e sociais também específicos (BARCELOS, 2004).

A escola em que ocorreu a investigação pertence à rede pública de instituiçõoes de ensino vinculadas à Secretaria Municipal de Educação de Cuiabá (SME), no Estado de Mato Grosso, e oferece espanhol como disciplina obrigatória e única língua estrangeira de sua matriz curricular do $6^{\circ}$ ao $9^{\circ}$ ano. Está localizada próxima ao centro da cidade em um bairro popular - seus habitantes pertencem majoritariamente a classes sociais pouco favorecidas. Como as escolas da rede municipal possuem autonomia para a escolha da língua estrangeira a ser adotada (inglês ou espanhol), decisão que deve ser encaminhada anualmente à SME para a distribuição da carga horária entre os professores, a

\footnotetext{
2 Segundo a autora, o inglês, historicamente, é a língua estrangeira mais ensinada nas escolas de ambos os países.
} 
implantação do espanhol nessa escola foi decidida, conforme relato da diretora, pela equipe gestora, "em uma decisão isolada nossa, de uma equipe gestora". Essa informação se torna relevante, pois as crenças da coordenadora pedagógica e da diretora foram preponderantes na opção pelo espanhol nessa escola. Daí a ênfase, neste artigo, de suas crenças para buscar compreender o papel atribuído ao ensino e aprendizagem do espanhol na escola em que atuam.

Para identificar as crenças das participantes desta pesquisa, analisei suas falas geradas por meio de entrevistas qualitativas (KING; HORROCKS, 2010), que geraram relatos e/ou depoimentos, os quais expressam a compreensão das participantes sobre suas experiências e, em decorrência, também sobre suas crenças. Entretanto, é preciso considerar que entrevistar é um processo interacional em que o pesquisador está ativamente moldando e administrando essa interação. Esse processo, em razão disso, envolve também considerar que as crenças, interesses, experiências e identidades do pesquisador imprimem impacto na pesquisa, em especial que sua voz está necessariamente presente na geração e na interpretação das vozes dos participantes (KING; HORROCKS, 2010).

\section{Crença 1: a aprendizagem do espanhol possibilita inserir-se no mercado (informal) de trabalho}

Essa primeira crença se alicerça na relação de imprescindibilidade entre a aprendizagem de línguas estrangeiras e o mercado de trabalho. No relato da coordenadora pedagógica, a partir da experiência de seu marido, essa crença está associada aos melhores postos no mercado de trabalho, que denomina "emprego bom".

Hoje você sabe que para o mercado de trabalho você tem que ter uma língua, né. Tem empresas que uma das perguntas na entrevista da seleção é se você fala inglês ou fala espanhol, se você tem uma língua diferente, né. Eu vou contar uma história do meu esposo. Meu esposo é administrador de fazenda desde que a gente casou. Então, era uma profissão que existia mercado de trabalho, porque ele era o que administrava a fazenda. Não seria o dono, mas ele administrava tudo, né. Com a evolução, quem é o administrador? Hoje, as empresas elas estão... como vou dizer? Terceirizados. Então eles têm empresas que vão fazer esse papel. Então o mercado de trabalho do administrador sumiu, né. E nós aqui em Mato Grosso, ele tinha vindo para uma empresa da borracha no interior de Mato Grosso, não quis mais ficar no interior de Mato Grosso e foi fazer um exame de... em uma empresa 
multinacional. Com toda a experiência que ele tinha, com toda a experiência que ele tinha como administrador e muito inteligente, ele não passou, porque quando ele teve que fazer a parte de língua estrangeira, porque era multinacional, ele tinha que viajar, para conversar com o pessoal do exterior, ele não tinha o inglês nem o espanhol, ele não falava fluentemente. Então, essa foi uma experiência amarga para ele, porque passou em tudo, seria a pessoa indicada para trabalhar em Primavera do Leste, se eu não me engano, e ele não pôde, ele perdeu o emprego porque ele não tinha uma língua. Ele não falava nem o inglês nem o espanhol. Ele tinha que ter uma língua estrangeira e ele não tinha. Ele perdeu o emprego e emprego bom. (Coordenadora pedagógica, entrevista 2, em 8 dez. 2010).

O relato da professora de espanhol sobre a resistência de alguns pais em relação ao ensino do espanhol desfila também a crença de que o conhecimento de línguas estrangeiras "nos abre portas profissionalmente".

Nós nos deparamos, por exemplo, com pais que, de repente, ele diz "não...", isso uma aluna me falou, "professora, eu estava estudando espanhol lá em casa, mas o meu pai falou assim, 'para que estudar essa porcaria, minha filha, vai estudar Português, Matemática, para que estudar isso?" Aí eu falei: "Mas o que você acha?", eu perguntei para ela. "Ah, eu gosto". "Então mostra para o seu pai o quanto é importante nós conhecermos um outro idioma, mostra para ele, aos pouquinhos ele vai compreender, né. "É porque meu pai nunca estudou, professora". "Então, compete a você, né, de repente mostrar para ele a beleza desse idioma, o quanto que é importante. Por quê? Porque é para o nosso futuro também, né, e é fato mais que relevante de que hoje o domínio de um novo idioma nos abre portas profissionalmente, né". (Professora de espanhol, entrevista 3, em 17 dez. 2010).

Entretanto, essas portas não significam necessariamente a perspectiva de bons empregos para os alunos. À luz do relato da coordenadora pedagógica, para os alunos isso não significa necessariamente competir pelos melhores postos de trabalho, mas apenas inserir-se em "um mercado de trabalho" que a Copa do Mundo de 2014 poderá proporcionar.

Então a gente sabe que o mercado de trabalho hoje, inclusive com a Copa do Mundo, porque em 2014 quem souber falar vai trabalhar com turista, como guia, vai ter um mercado de trabalho. (Coordenadora pedagógica, entrevista 2, em $8 \mathrm{dez}$. 2010). 
Já à luz do relato da professora de espanhol, o conhecimento da língua poderá possibilitar a inserção dos alunos no que parece ser o mercado informal de trabalho, na condição de vendedores ambulantes de cachorro-quente e/ou água.

[...] "mas se você puder, não deixe de estudar, né, isso vai abrir portas". Aí eu mostro "estão vindo aí as Olimpíadas, a Copa. Então, de repente, vocês vão vender um cachorro-quente na porta do estádio, água, e vai aparecer alguém que vai falar em espanhol com você, mas você vai saber, vai entender, né, porque vai te pedir uma água, você já vai saber o que ele está falando, é água”. (Professora de espanhol, entrevista 3, em 17 dez. 2010).

O papel atribuído tanto pela coordenadora pedagógica quanto pela professora ao ensino de espanhol aos alunos, dessa forma, parece ser o de facultar o acesso a "um mercado de trabalho" que, não necessariamente, implique os melhores postos. Como explica a professora, a aprendizagem do espanhol poderá ser importante para que seus alunos possam se inserir em um mercado de trabalho que parece ser o informal, pois, como sabemos, os vendedores de cachorroquente e/ou água que trabalham "na porta do[s] estádio[s]" brasileiros raramente possuem registro na carteira de trabalho e, portanto, enquadram-se na parcela da população economicamente ativa brasileira que trabalha na informalidade.

Essa crença das participantes, portanto, parece situar lugares fixos para o papel das línguas estrangeiras no mercado de trabalho: aqueles que poderão utilizá-las para competir pelos melhores empregos e aqueles que estudam na escola pública e, portanto, não necessariamente poderão valer-se delas para competir pelos melhores empregos. Além disso, não parece possibilitar que os alunos sonhem com melhores perspectivas. Ao contrário, colabora para fixar o lugar a que esses alunos pertencem, de modo que, mesmo com o conhecimento de uma língua estrangeira, apontado pelas participantes como a "válvula de escape" da condição socioeconômica em que se encontram (a possibilidade de "empregos bons" e a "abertura de portas profissionalmente"), não ocorra mudança de status quo e se mantenha a estratificação social.

\section{Crença 2: o espanhol é a língua estrangeira que melhor atende aos alunos de escola pública}

A análise dessa segunda crença está ancorada na suposta facilidade para aprender espanhol. Essa facilidade é apontada pela diretora como o fator primordial da decisão da inserção do espanhol como única língua estrangeira oferecida pela escola que dirige. 
Seria bonito eu falar para você que foi uma decisão colegiada, que a gente sentou no coletivo com os pais, votamos, aí a gente colocou para os alunos, aí os alunos opinaram, os professores opin... Não, não aconteceu nada disso. Foi uma decisão, sim, isolada da escola, da direção da escola. Até por ter esse mito, né, essa coisa, é a língua mais fácil. Então a gente tem essa tendência de trilhar esses caminhos pelo menos, assim, a princípio, mais fáceis. Então, nessa lenda, nessa coisa cultural, em uma decisão isolada nossa, de uma equipe gestora... não foi minha, mas da equipe gestora. Participei ativamente do processo, mas não houve assim... A gente não teve esse momento oficial de escolha, de votação do colegiado, não teve nada disso não. (Diretora, entrevista 1, em 1 dez. 2010).

Da mesma forma, a escolha por "uma língua mais fácil” se ampara na constatação da diretora de que a classe trabalhadora e os alunos não veem sentido, não compreendem a importância da aprendizagem de uma língua estrangeira na contemporaneidade.

Aprender uma língua estrangeira é extremamente importante para a educação dos alunos. E infelizmente esse, essa visão, essa ideia, ela é só arraigada na classe média, classe média alta. Para a classe trabalhadora isso não tem valor algum. Infelizmente esse valor foi colocado para os alunos de classe média, de escola particular, que tem bons professores de línguas, e que eles complementam nas escolas de línguas, né. Então é importante, mas infelizmente é um universo completamente diferente nessa nossa classe social, é, que a gente está habituada. É, não é um sonho, um desejo, não é uma expectativa trabalhar... Porque, é, é, são situações da classe média alta, viajar para o exterior, os melhores empregos, porque infelizmente a classe trabalhadora ela não sonha, ela não, é, dos melhores empregos e para os melhores empregos normalmente precisa ter esse conhecimento de uma outra, de uma segunda língua. E infelizmente isso é uma realidade que é difundida somente, que não é nem trabalhada, eles já nascem, já é cultural aí do metier, infelizmente. A segunda língua é uma disciplina que a criança, o adolescente, o jovem precisa tirar nota, não é uma língua para ele desenvolver socialmente, não é uma língua que ele precisa para o mercado de trabalho absorvê-lo de maneira mais proveitosa, absolutamente não é. Aqui na nossa realidade é uma matéria, é uma disciplina e ele precisa passar de ano, precisa de uma média, uma nota. Não para o mercado de trabalho nem para a sua condição social, cultural ser melhorada. Eu penso assim. (Diretora, entrevista 1, em 1 dez. 2010). 
A constatação de que a classe trabalhadora e os alunos não atribuem importância à aprendizagem de línguas estrangeiras abrange os pais dos alunos que, conforme o relato da coordenadora pedagógica, ainda não têm noção ou não se conscientizaram sobre a "importância de uma língua estrangeira para o mundo atual".

O interesse do pai não é só fundamental para a língua estrangeira como para as demais, mas ele não tem, talvez, uma noção de que o filho dele, no mundo evoluído da comunicação que tem hoje, a importância, ele não consegue talvez, talvez é até uma falha da escola não passar isso para eles ou eles ainda não se conscientizaram da importância de uma língua estrangeira para o mundo atual [...] Então isso leva que ele não vê esse outro lado. (Coordenadora pedagógica, entrevista 2, em 8 dez. 2010).

Portanto, as constataçóes de ambas as participantes justificariam o ensino de uma língua "mais fácil", uma vez que, à luz do relato da diretora, aprender uma língua estrangeira envolve situações específicas, como "viajar para o exterior" e "os melhores empregos", que não se configuram em sonhos, desejos ou expectativas da classe trabalhadora. Ainda segundo seu relato, a língua estrangeira representa apenas "uma matéria", "uma disciplina" que o aluno precisa tão só de uma nota para ser aprovado, ignorada a condição de ser necessária para os melhores empregos, nem mesmo "para a sua condição social e cultural ser melhorada". Dessa forma, " $a$ língua mais fácil" é transformada em sinônimo de a língua que melhor atende a uma parcela da população que ainda não tem noção ou não se conscientizou no tocante à importância de uma língua estrangeira para o mundo atual - os alunos de escola pública -, ou ainda, de acordo com a análise da crença 1 , não necessariamente ocupará os melhores postos no mercado de trabalho.

A crença de ser a língua que melhor atende aos alunos de escola pública parece, portanto, também demarcar discursivamente dois grupos definidos: aqueles que já se conscientizaram sobre a importância da língua estrangeira e aqueles que dela ainda não se conscientizaram. Os pais e os alunos de escola pública pertencem, palmilhando os relatos da coordenadora pedagógica e da diretora, respectivamente, ao segundo grupo. Portanto, se os alunos de escola pública pertencem ao grupo daqueles que ainda não se conscientizaram sobre a importância de uma língua estrangeira para o mundo atual, justifica-se a decisão pelo ensino de uma língua estrangeira considerada " $a$ mais fácil". Em adendo, como argumenta a diretora, a língua estrangeira representa apenas "uma matéria", "uma disciplina" em que o aluno precisa tão só de uma nota 
para ser aprovado. É nesse círculo vicioso que discursivamente a adoção do espanhol, assim como na análise da crença 1, parece contribuir para a reprodução e manutenção do status quo e da estratificação social, dado que, a partir dos relatos das participantes da pesquisa, não se abre o ensejo de transformação social.

\section{Considerações finais}

O objetivo do ensino de espanhol no Brasil encarta sua aspiração como elemento de integração regional, conforme expressam os documentos que regulam o ensino no Brasil. Associado a isso, mesmo que a ênfase ocorra no ensino de um espanhol homogêneo para a comunicação internacional, defendida pelos órgãos de difusão internacional da língua do governo espanhol, esta pesquisa parece indicar que existem papéis outros, também atribuídos ao ensino e aprendizagem da língua espanhola, que precisam ainda ser investigados e questionados.

Primeiramente, a inserção do ensino de espanhol na escola em que ocorreu esta investigação parece corroborar a crença da escola pública como "a escola dos pobres", que disponibiliza "uma educação incapaz de promover mudança de status quo", uma educação que "acaba impedindo as transformações sociais em direção a uma sociedade menos estratificada e mais igualitária” (ASSISPETERSON et al., 2010, p. 220-222). Contribui, ainda, para impedir, ao menos no âmbito do discurso, alterações no processo das histórias dos alunos, já que, de acordo com as crenças das participantes desta pesquisa, a escola não figura assumir um compromisso para que, de fato, os alunos sonhem com melhores perspectivas a partir da aprendizagem da língua espanhola, apesar de as participantes acreditarem na imprescindibilidade entre o conhecimento de línguas estrangeiras e os melhores postos no mercado de trabalho.

Não se trata, contudo, de "demonizar a escola pública” (PAIVA, 2011). Se, por um lado, a escola em que ocorreu esta pesquisa parece constituir um lugar de manutenção e reprodução do status quo, por outro pode representar também um lugar de sonhos, de desejos e anseios por uma vida melhor e uma sociedade menos estratificada. É nessa dicotomia que acredito possa a pesquisa de crenças sobre ensino de línguas contribuir significativamente para (re)pensar o papel que estamos atribuindo ao ensino e à aprendizagem do espanhol. Afinal, possibilita criar espaços para que crenças sejam questionadas e desconstruídas, contribuindo assim para que outros relatos e/ou depoimentos sobre aprendizagem de línguas estrangeiras possam ser desvendados. 


\section{Referências}

ASSIS-PETERSON, A. A.; COX, M. I. P.; SANTOS, D. A. G. Crenças \& discursos: aproximações. In: SILVA, K. A. (Org.). Crenças, discursos \& linguagem. Campinas: Pontes, 2010. v. 1, p. 195-226.

BARCELOS, A. M. F. Cognição de professores e alunos: tendências recentes na pesquisa de crenças sobre ensino e aprendizagem de línguas. In: BARCELOS, A. M. F.; VIEIRA-ABRAHÃO, M. H. (Org.). Crenças e ensino de línguas: foco no professor, no aluno e na formação de professores. Campinas: Pontes, 2006. p. 15-42.

BARCELOS, A. M. F. Crenças sobre aprendizagem de línguas, Linguística Aplicada e ensino de línguas. Linguagem \& Ensino, Pelotas, v. 7, n. 1, p. 123156, 2004. Disponível em: <http://www.revistas.ucpel.tche.br/index.php/rle/ article/download/217/184>. Acesso em: 21 jul. 2013.

BARCELOS, A. M. F. Reflexões acerca da mudança de crenças sobre ensino e aprendizagem de línguas. Revista Brasileira de Linguistica Aplicada, Belo Horizonte, v. 7, n. 2, p. 109-138, 2007. Disponível em: <http://www.scielo.br/ pdf/rbla/v7n2/06.pdf>. Acesso em: 21 jul. 2013.

BARCELOS, A. M. F.; KALAJA, P. Introduction to Beliefs about SLA Revisited. System, v. 39, n. 3, p. 281-289, Sept. 2011.

DEL VALLE, J. La lengua, pátria común: la hispanofonía y el nacionalismo panhispánico. In: . La lengua, pátria común? - ideas e ideologias del español. Madri: Iberoamericana; Frankfurt am Main: Vervuert, 2007. p. 31-56. GIL, G. O ensino do inglês, do português e do espanhol como línguas estrangeiras no Brasil e na Argentina: uma comparação glotopolítica. Revista Helb, ano 3, n. 3, 2009. Disponível em: <http://www.helb.org.br/index. php?option $=$ com_content $\& v i e w=$ article $\& i d=108$ :o-ensino-do-ingles-doportugues-e-do-espanhol-como-linguas-estrangeiras-no-brasil-e-na-argentinauma-comparacao-glotopolitica\&catid =1082: ano-3-no-03-12009\&Itemid=10>. Acesso em: 6 fev. 2011.

LAGARES, X. C. A ideologia do panhispanismo e o ensino do espanhol no Brasil. Políticas Lingüisticas, año 2, v. 2, p. 85-110, oct. 2010.

PAIVA, V. L. M. O. Ilusão, aquisição ou participação. In: LIMA, D. C. (Org.). Inglês em escolas públicas não funciona? - uma questão, múltiplos olhares. São Paulo: Parábola, 2011. p. 33-46.

PAN, L.; BLOCK, D. English as a "Global Language" in China: An Investigation into Learners' and Teachers' Language Beliefs. System, v. 39, n. 3, p. 391-402, Sept. 2011. 
PARAQUETT, M. O papel que cumprimos os professores de espanhol como língua estrangeira (E/LE) no Brasil. Cadernos de Letras da UFF, Niterói, n. 38, p. 123-137, 2009. Disponível em: <http://www.uff.br/cadernosdeletrasuff/38/ artigo7.pdf>. Acesso em: 21 jul. 2011.

VILLA, L.; DEL VALLE, J. ¡Oye!: língua e negócio entre o Brasil e a Espanha. Calidoscópio, São Leopoldo, v. 6, n. 1, p. 45-55, 2008. 